\title{
Mulher, esposa e mãe na ciência e tecnologia
}

\author{
Rayane Monique Bernardes Loch' (iD 0000-0002-9949-6813 \\ Kelly Beatriz Vieira Torres² (iD 0000-0002-0884-8423 \\ Carolina Reciate Costa ${ }^{3}$ (iD 0000-0001-7230-7763 \\ 'Universidade Federal de Viçosa, Departamento de Engenharia Química, Viçosa, MG, \\ Brasil. 36570-900 \\ 2Universidade Federal de São João Del-Rei, Departamento de Estatística, Física e \\ Matemática, Ouro Branco, MG, Brasil. 36420-000 \\ șUniversidade Federal de São João Del-Rei, Departamento de Química, Biotecnologia e \\ Engenharia de Bioprocessos, Ouro Branco, MG, Brasil. 36420-000
}

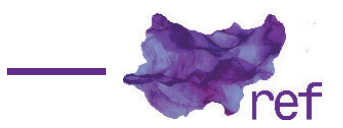

Resumo: Neste artigo se discute as desigualdades de gênero nos cursos de engenharia de um campus de uma universidade pública, na perspectiva de discentes de ambos os sexos e pesquisadoras/ docentes do sexo feminino. Foram analisados o número de discentes mulheres ingressos e egressos por curso, o tempo de integralização na graduação, os influenciadores para a escolha da carreira, a discriminação de gênero na academia, o número de mulheres nos departamentos, a conciliação entre familia, maternidade e carreira, bem como os obstáculos enfrentados no mercado de trabalho pelo público feminino.

Palavras-chave: gênero; engenharia; carreira; família; maternidade.

\section{Woman, Wife and Mother in Science and Technology}

Abstract: This paper discusses gender inequalities in engineering courses at a campus of a public university, from the perspective of both genders, and also from female researchers/professors. We analyzed the number of female students that started and finished each course, graduation time, influencers for the career choice, gender discrimination in academic community, number of women in departments, conciliation between family, maternity and career, as well as obstacles faced in the work market by the female public.

Keywords: Gender; Engineering; Career; Family; Maternity.

\section{Introdução}

Até aproximadamente o final dos anos 60, ser mulher significava exercer a maternidade, cuidar do lar, sonhar com um casamento que atendia aos interesses sociais e econômicos da família, realizar tarefas leves e delicadas que não exigissem esforço físico e mental (Gustavo VENTURI; Marisol RECAMÁN; Suely de OLIVEIRA, 2014, p. 1-248).

Por intermédio de um histórico de luta e resistência das mulheres, a partir da década de 70, as mulheres brasileiras passaram a ocupar o mercado de trabalho, assumindo uma nova posição na sociedade. Hoje, dificilmente alguém ousa afirmar que uma mulher não possui condições para cargos políticos e para se tornar engenheira, médica, empresária ou qualquer outra profissão popularmente tida como masculina (VENTURI; RECAMÁN; OLIVEIRA, 2014, p. 1-248). Contudo, a realidade tem mostrado que as relações desiguais de gênero ainda existem. 
Desde a infância, as atividades propostas para as crianças ainda são sexistas: meninos são incentivados a desenvolver a objetividade, enquanto as meninas são incentivadas a desenvolver habilidades mais subjetivas. Essa diferenciação é construída ao longo de suas infâncias e adolescências de tal maneira que quando chegam à idade de escolher uma profissão, suas decisões são reflexos de suas expectativas sociais (Marília Gomes de CARVALHO; Josimeire de Lima SOBREIRA, 2008, p. 889-904). No que se refere à participação das mulheres na ciência, por muito tempo, as mulheres não puderam desenvolver pesquisas nem mesmo como auxiliares, pois eram impedidas de frequentar as instituições de ensino. Ser mulher significaria estar destinada a assumir o cuidado da casa, dos filhos e do marido. Embora as universidades tenham surgido no século XII, as mulheres só tiveram realmente o direito de estudar no final do século XIX e início do século XX (Fabiane Ferreira da SILVA, 2012, p. 1-149).

As últimas décadas trouxeram consideráveis avanços no que diz respeito à inserção e à participação das mulheres no campo científico. Atualmente, é possível perceber o número significativo de mulheres em muitas universidades do país como docentes/pesquisadoras e estudantes de graduação e pós-graduação.

No Brasil, essa entrada de mulheres nos cursos superiores foi acelerada à medida que se avançava a industrialização e os movimentos de mulheres iam ganhando voz, exigindo, além do voto, o acesso à educação e ao trabalho, questionando então a sociedade patriarcal que negava às mulheres esses direitos (Maria Mary FERREIRA, 2003, p. 189-201).

Atualmente, observa-se que o tema tem sido cada vez mais discutido, e pode ser considerado uma vertente dos estudos de gênero que procura dar visibilidade às desigualdades construídas socialmente entre a mulher e o homem também no ambiente científico/acadêmico, por meio da análise das diferenças de sexos. Os enfoques principais se situam nas diferenças de gênero em relação à produção científica dos pesquisadores, nos papéis e atividades científicas, na desigualdade em acesso a profissões, inclusão em carreiras de ciência e tecnologia, no acesso de mulheres ao mercado de trabalho e na sua inserção em carreiras de nível superior (Elinielle Pinto BORGES, 2014, p. 1-104).

Além disso, a trajetória da ciência mostra uma concentração por gênero em determinadas áreas do conhecimento. Em geral, os homens estão mais presentes nas áreas exatas e as mulheres nas áreas humanas e sociais. Esse fenômeno de segregação por gênero nas áreas na ciência ou disciplinas é conhecido como o fenômeno de segregação territorial, do inglês gender tracking (BORGES, 2014, p. 1-104).

São discutidas duas propostas para se explicar esta falta de proporção entre homens e mulheres nas áreas de ciências e tecnologias. A primeira atribui o problema a diferenças biológicas, cognitivas ou de socialização entre os dois sexos. Os argumentos mais comuns em favor desta hipótese são a falta de controle emocional da mulher, indecisão, falta de agressividade para competir e dificuldade para suportar pressão. A segunda perspectiva propõe que a questão de mulheres em ciência e tecnologia é resultado de estruturas institucionais inapropriadas e não da inaptidão feminina para essas áreas (Thereza Amélia SOARES, 2001, p. 281-285).

Segundo Maria Cristina Hayashi et al. (2007, p. 169-187), os fatores que mais se destacam para o afastamento de mulheres da comunidade científica são:

- Dificuldade em conciliar a vida familiar com a carreira profissional, submetendo-se à dupla jornada de trabalho (profissão e tarefas domésticas), sobrecarregando a mulher. $O$ ingresso no mercado de trabalho revela o mesmo panorama desigual da distribuição das tarefas do lar associada à falta de iniciativas públicas (como creches e escolas em tempo integral), levando muitas mulheres, principalmente às de baixa renda e com baixo nível de escolaridade, a se dividirem entre o mercado de trabalho e a realização dos afazeres domésticos, por não poderem contratar no mercado tais serviços, tendo como produto a "dupla jornada de trabalho feminino".

- Tendência em não ter filhos, encarando a gravidez como um problema para o desenvolvimento de sua carreira acadêmica. Segundo o IBGE, a taxa de fecundidade diminuiu significativamente ao longo dos anos, observando-se então que um menor número de filhos estaria relacionado a um maior engajamento no mercado de trabalho. Além disso, o papel da maternidade sobre o engajamento da mulher no mercado de trabalho poderia ser um dos fatores que estaria explicando o diferencial de salário e de ocupações entre homens e mulheres (Elaine Toldo PAZELLO, 2006, p. 507-538). Uma pesquisa internacional a respeito da vida profissional e privada de homens e mulheres altamente qualificados relata que quanto mais bem-sucedido o homem, mais provavelmente irá encontrar uma esposa e se tornará pai. Já das mulheres igualmente qualificadas, 49\% não têm filhos, enquanto 75\% dos homens têm. Isso evidencia que, além dos desafios de carreira, é necessário enfrentar também o desafio da maternidade (Greyce Rocha BELTRAME; Tagma Marina Schneider DONELLI, 2012, p. 206-217).

- Dificuldades de se ausentar para participação em congressos e visitas científicas, além da diminuição de produção acadêmica. Um estudo realizado por Maria Lúcia Coutinho Rocha e Rodrigo Coutinho Rocha (201 1, p. 61-80), ao entrevistarem executivas ou gerentes gerais que eram mães, mostrou que, ao exercerem a maternidade, as mulheres entrevistadas relataram 
algumas estratégias utilizadas para a conciliação da maternidade e carreira. Entre elas, horário de trabalho fixo, evitar horas extras e reduzir as viagens. Como estratégia de investimento em suas carreiras, acreditavam que passaram a se concentrar mais em suas tarefas, tendo um incentivo maior para trabalhar e evitar a demissão.

- Persistência do machismo, estereótipos sexuais e preconceitos contra a mulher, levando à falta de condições e de estímulo para sua vida pessoal e profissional.

Neste trabalho, se busca analisar as relações de gênero nos cursos de engenharia do Campus Alto Paraopeba (CAP) da Universidade Federal de São João Del-Rei (UFSJ), atualmente constituído pela engenharia de bioprocessos, engenharia química, engenharia civil, engenharia de telecomunicações e engenharia mecatrônica. O campus está instalado no interior de Minas Gerais (cerca de 100 km de Belo Horizonte), em meio ao polo de grandes siderúrgicas brasileiras.

O estudo constitui-se na análise de dados obtidos por questionários on-line, disponibilizados para discentes de graduação (de ambos os sexos), entrevista com docentes/pesquisadoras da mesma instituição, dados disponibilizados pela Divisão de Acompanhamento e Controle Acadêmico (DICON/UFSJ) e o site da UFSJ. Os temas analisados foram: número de discentes mulheres ingressas e egressas por curso, tempo de integralização de curso, influenciadores para a escolha da carreira, discriminação de gênero na academia, número de mulheres nos departamentos da UFSJ, conciliação entre família, maternidade e carreira, bem como obstáculos enfrentados no mercado de trabalho pelo público feminino.

\section{Caracterização do Público Participante}

No intuito de estudar as relações de gênero no meio acadêmico de um campus de engenharia, dois públicos diferentes foram utilizados: discentes de ambos os sexos dos cursos do CAP/UFS e pesquisadoras/docentes. A pesquisa é baseada na análise estatística dos dados obtidos, por questionários, entrevista semiestruturada e base de dados da UFSJ, como segue:

(a) análise do número de ingressos(as) e egressos(as) graduandos(as) da UFSJ/CAP, desde a sua criação, em 2008, até o ano de 2017, por intermédio dos dados disponibilizados pela Divisão de Acompanhamento e Controle Acadêmico (DICON) da UFSJ.

(b) análise de questionário on-line respondido por 238 discentes de engenharia da UFSJ/ CAP, de ambos os sexos, desenhado para abranger um público aleatório maior e tornar a pesquisa impessoal, sendo possível identificar as diferenças e semelhanças nas respostas dadas por homens e mulheres. Evitou-se abordar diretamente a temática gênero na tentativa de reduzir o "pré-conceito" que as(os) discentes poderiam ter inicialmente, ao ler o questionário.

(c) análise do número de docentes/pesquisadoras em todos os departamentos dos campi da UFSJ (Campus Alto Paraopeba - CAP; Campus Centro Oeste Dona Lindu - CCO; Campus Sete Lagoas - CSL; Campos Santo Antônio - CSA; Campus Dom Bosco - CDB e Campos Tancredo Neves), a partir dos dados obtidos pelo site da UFSJ.

(d) entrevista presencial e anônima realizada com 5 professoras de diferentes departamentos da UFSJ/CAP. As questões abordadas incluíram conciliação de carreira e maternidade, influenciadores e incentivos para a escolha do curso, comportamento dos discentes em sala de aula, e atuação no mercado de trabalho.

\section{Resultados e Discussōes}

No total, 238 estudantes participaram da pesquisa on-line, sendo 179 (75\%) do sexo feminino e 59 (25\%) do sexo masculino, tornando-se possível avaliar o perfil das(os) discentes da engenharia. Os cursos com o maior número de respostas foram o de engenharia química e de bioprocessos.

\section{Mulheres nas engenharias}

No Brasil, o ensino de engenharia iniciou-se com duas escolas militares: a Escola de Artilharia e Arquitetura Militar, em 1696, na Bahia, e a Academia Real Militar, em 1855, no Rio de Janeiro. Por ser militar, consequentemente havia uma recusa à entrada de mulheres na profissão (Márcia Terra da SILVA, 1992, p. 1-120). Porém, nos últimos anos, este panorama tem melhorado, mas longe de atingir o ideal, como exemplificado abaixo, por meio da análise do número de ingressos nos cursos de engenharia do CAP//UFSJ.

Os resultados para o período de 2008 a 2017 mostram que 1898 mulheres se matricularam em um dos 5 cursos de engenharia do CAP//UFSJ (bioprocessos, química, civil, mecatrônica e telecomunicações), contrapondo-se a 3097 homens inscritos. Este número corresponde a 39\% do número total. No entanto, observa-se pontualmente que há uma disparidade entre o número de mulheres para cada engenharia (vide Gráfico 1). 


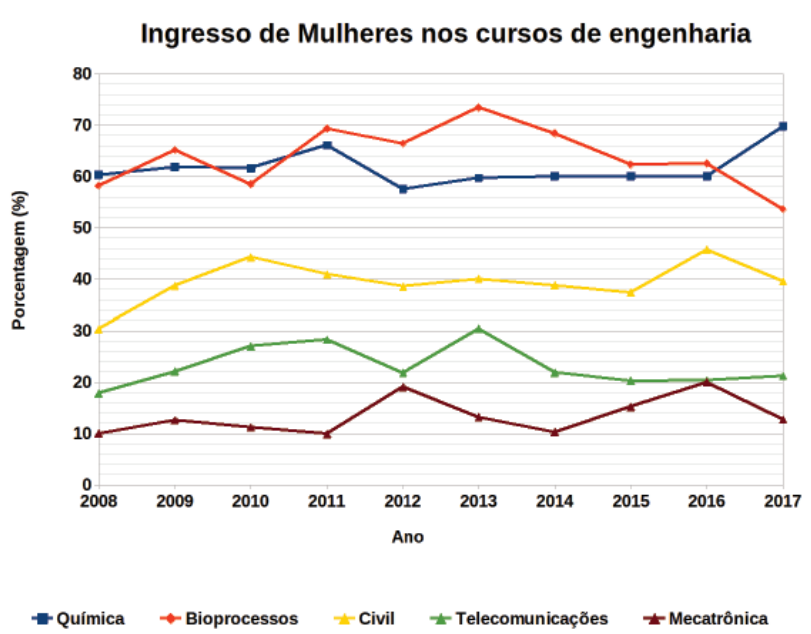

Gráfico 1 - Relação de mulheres inscritas nos cursos de engenharia da UFSJ/CAP (engenharia civil, engenharia de bioprocessos, engenharia química, engenharia de telecomunicações e engenharia mecatrônica)

Fonte: Dados da pesquisa.

\#PraTodoMundoVer Gráfico ilustrando a relação de mulheres inscritas em cursos de engenharia da UFSJ no ano de 2008 a 2017. O gráfico indica maior concentração de mulheres nas engenharias de bioprocessos e química; na posição intermediária, tem-se a engenharia civil, e o menor número de mulheres, entre 10 e $20 \%$, está na engenharia de telecomunicações e mecatrônica. O

eixo vertical, que corresponde à porcentagem, está dividido em $0,10,20,30,40,50,60,70$ e 80 . O eixo horizontal diz respeito aos anos de 2008 a 2017.

A participação feminina está em $13 \%$ e $23 \%$, na média, respectivamente, para os cursos de mecatrônica e telecomunicações. Na engenharia civil, o número de mulheres ingressantes é cerca de 39\%, na média. Em contrapartida, na engenharia química e na de bioprocessos, há maior índice de mulheres (62\% e 64\%, respectivamente). A baixa participação feminina em algumas áreas da engenharia é atribuída aos estereótipos masculinizados presentes em algumas destas áreas, o que justificaria o afastamento das mulheres em carreiras como engenharia mecatrônica e engenharia de telecomunicações (Gráfico 1).

Uma das possibilidades para essa grande variação da presença feminina entre esses conjuntos de dados extremos é o menor contato das mulheres em fase escolar com matérias relacionadas à programação, à eletrônica e à computação, existente nos cursos de mecatrônica e telecomunicações, bem como falta de apoio e incentivo da família e escola. Todos esses fatores foram citados pelas estudantes ao responderem o formulário on-line, evidenciando a limitação e os obstáculos que as mulheres enfrentam na escolha de uma carreira nas engenharias. Ao perguntar se consideravam haver poucas mulheres nas engenharias, $75,6 \%$ das(Os) participantes responderam que sim, apresentando como justificativas a falta de incentivo por parte da família, amigos e escola, como mostram alguns relatos:

Sim, há poucas mulheres. Pelo grande preconceito, e também baixo incentivo enquanto crianças e durante toda a vida, começando pelos brinquedos que na maioria não são dados (estudante do sexo feminino de engenharia mecatrônica, 24 anos em 2017).

Sim, há poucas mulheres. Existe uma cultura que nos direciona a cursos que envolvem o 'relacionar com' e 'atender' pessoas, como nutrição, medicina, psicologia, farmácia, recursos humanos (estudante do sexo feminino de engenharia química, 21 anos em 2017).

Sim. Nunca tive contato com uma mulher atuando como engenheira em nenhuma empresa, o que é bem diferente do que acontece com os homens. Diariamente vejo vários deles, seja em cargos de chão de fábrica ou de chefia (estudante do sexo feminino de engenharia química, 24 anos em 2017).

Segundo Torres et al. (2017, p. 140-156), escolas situadas próximas à UFSJ/CAP ainda preconizam que determinadas carreiras são mais bem desenvolvidas por homens, e pais/ responsáveis afirmam que suas filhas devem permanecer em casa, cuidando dos afazeres domésticos (TORRES et al., 2017), revelando como jovens meninas (de 12 a 18 anos) têm sido incentivadas nas escolas, família e sociedade para ingressarem em carreiras das ciências exatas. Este discurso também é evidenciado nos formulários on-line:

O incentivo para as mulheres cursar engenharia ainda não é o suficiente, visto que nas escolas há, ainda, um pensamento que as mulheres não conseguem absorver o mesmo tanto que os homens na área de exatas. Além do mercado de trabalho ainda não valorizar, suficientemente, a mão de obra feminina (estudante do sexo feminino de engenharia mecatrônica, 18 anos em 2017).

Mulheres não são incentivadas a fazer cursos de engenharia ou algum curso relacionado à área de exatas. Uma lástima. A propósito, tenho amigas, conhecidas e mãe que apresentam aptidão natural para as ciências exatas, mas, por forças de influência da sociedade e más

' Baseados na lista de discentes ingressos e egressos fornecida pela DICON/UFSJ. 
interpretações religiosas são orientadas à dedicação integral a família e marido (estudante do sexo masculino de engenharia mecatrônica, 21 anos em 2017).

Segundo Maria Ligia Moreira e Lea Velho (2010), essas desigualdades são resultado de uma educação que atribui papéis diferentes para meninos e meninas, o que geralmente acaba influenciando no desenvolvimento de características pessoais e profissionais. Nesse processo, os meninos são vistos como aptos para as disciplinas de exatas e as meninas para as áreas sociais e de saúde. E mesmo quando as mulheres ascendem nas carreiras acadêmicas em áreas onde teoricamente seriam mais aptas, enfrentam desafios para os quais muitas vezes não foram educadas ou estimuladas, como processos acadêmicos competitivos ou o compromisso de dedicação exclusiva ao trabalho científico (MOREIRA; VELHO, 2010, p. 279-308).

As mulheres enfrentam ainda discriminações de gênero no ambiente universitário e muitas vezes são vítimas de preconceitos e descrédito com relação a suas capacidades, necessitando comprovar continuamente sua competência profissional, como mostra o relato: Sim, há poucas mulheres. O curso ainda é visto como um curso masculino e muitas vezes mulheres são menosprezadas por isso, como se fossem menos capazes (estudante do sexo feminino de engenharia de bioprocessos, 21 anos em 2017).

O formulário on-line revelou que $24,4 \%$ dos entrevistados, de ambos os sexos, discordaram haver poucas mulheres na engenharia. Dentre as justificativas, a mais citada foi que o número de mulheres nas engenharias (em geral) tem crescido, mas reconhecem que os cursos de engenharia de telecomunicações e mecatrônica ainda possuem pouca representatividade feminina.

Dentre os respondentes do sexo masculino para a mesma questão, a grande maioria mostra empatia para as questões de desigualdade de gênero:

Ainda há uma "masculinização" da engenharia, mas isso tem mudado, felizmente (estudante do sexo masculino de engenharia de telecomunicações, 27 anos em 2017).

Muitas são erroneamente levadas a crer que a engenharia é um espaço avesso a elas e um desafio o qual elas podem não ser capacitadas suficiente (estudante do sexo masculino de engenharia de bioprocessos, 27 anos em 2017).

Alguns cursos de engenharia ainda são percebidos como espaços naturalmente masculinos, como engenharia mecânica e mecatrônica, enquanto outros, como engenharia química e de bioprocessos, possuem maioria de mulheres. A engenharia, no geral, parece ter paridade, mas o papel de gênero continua agindo na definição do que é masculino e do que é feminino: as mulheres devem estudar a delicada natureza, os homens devem estudar as brutas máquinas (estudante do sexo masculino de engenharia civil, 21 anos em 2017).

No que se refere à necessidade de preparar e incentivar meninas para as áreas das exatas na opinião dos graduandos do sexo masculino, $61 \%$ dos respondentes concordam, 16\% discordam e $23 \%$ são indiferentes. Para a mesma questão, 3,3\% das respondentes do sexo feminino acreditam que não há necessidade de incentivar meninas para as áreas das exatas. Algumas discentes deste grupo declararam ter tido algum tipo de incentivo por parte da família para se tornarem engenheiras ou por terem acesso a brinquedos de desenvolvimento de noção espacial, lógica ou fenômenos da natureza (kits de ciência). Apenas uma discente $(0,6 \%$ ) declarou ter tido nenhum incentivo, mas mesmo assim prosseguiu em sua escolha em cursar engenharia química (que é o curso que apresenta mais representatividade feminina). Há que se perguntar se a segregação por curso de engenharia (segregação territorial, como mencionado por Borges (2014, p. 1-104), evidenciada aqui e nos questionários, mostra que a mulher ainda opta por uma área que seja mais confortável para ela e a sociedade.

Quanto às motivações que levam mulheres a não cursarem engenharia, 50,7\% das mulheres responderam que a incerteza de conseguir um emprego como engenheira contribui para o afastamento do sexo feminino da área. Os demais motivos citados foram o desinteresse de mulheres, falta de incentivo da família e dificuldade do curso.

Pelos motivos citados acima, 54\% de mulheres responderam que, ao ingressarem no curso, já imaginavam que poderiam sofrer discriminação por gênero. Situações de preconceito existentes por parte dos professores foram relatadas por $77 \%$ das discentes, mostrando que o ambiente na engenharia é mais desfavorável para o sexo feminino. Constantemente foram relatadas falas de docentes de ambos os sexos menosprezando o sexo feminino em relação ao masculino, durante suas aulas, como, por exemplo, "esse exercício é tão fácil que até as meninas conseguirão fazer" ou "lugar de mulher não é na engenharia". O relato sobre docentes e seus discursos sexistas mostra o quanto a cultura da desigualdade de gênero é enraizada, sendo mulheres capazes de reproduzir um discurso machista e que afeta as alunas durante o curso.

\section{Relação de mulheres formadas nos cursos de engenharias}

Com o intuito de avaliar o desempenho das graduandas nos cursos de engenharia da UFSJ/CAP, foi analisada a razão do número de egressos por ingressos, considerando 4 tempos de 
formação (5 anos; 5,5 anos; 6 anos e 6,5 anos) iniciados em 3 momentos diferentes ( $1^{\circ}$ semestre dos anos de 2008, 2009 e 2010) para cada curso. A análise não leva em consideração as mudanças internas e externas de curso, trancamento de matrícula e evasão.

Em geral, para todas as engenharias, a razão do número de egressos por ingressos para as mulheres é superior a dos homens, considerando as três amostras. O tempo de integralização dos cursos de engenharia é de 5 anos, caso não haja nenhuma reprovação em disciplinas. A estimativa para o tempo médio de integralização, para o público feminino observado na análise, é de 6 anos para a engenharia civil, 5,5 a 6,5 anos para a engenharia química, de 6 a 6,5 anos para as engenharias de bioprocessos, telecomunicações e mecatrônica. Os dados indicam que, apesar do pouco incentivo e do estereótipo masculino que as exatas carregam, as discentes possuem melhor desempenho durante a graduação. Uma das hipóteses possíveis para esse fato pode ser atribuída a uma maior autocobrança, principalmente pela insegurança que há quanto ao mercado de trabalho, onde a mulher acredita que deva possuir um currículo mais completo, para que suas chances aumentem em relação aos homens, além de um maior comprometimento e responsabilidade.

Em alguns casos, homens concluem o curso de graduação mais rápido que mulheres, como é o caso do curso de engenharia civil para os dados de ingresso em 2010/1, média de 5 anos de formação. Possivelmente, houve um acúmulo de homens que não se formaram nos anos anteriores, levando, assim, a uma taxa maior de obtenção de títulos nos anos subsequentes. Embora o número de homens ingressantes nos cursos seja superior em todos os anos analisados (Gráfico 1), observa-se que o tempo estimado de integralização do curso pelas graduandas é inferior ao tempo estimado para os homens, mesmo não considerando os fenômenos de evasão ou mudança de curso. Esta tendência é observada para os outros cursos de engenharia, evidenciando que elas possuem um melhor rendimento, sob um ambiente desfavorável de apoio e incentivo - além da indicação de que elas possuem comportamentos de autocontrole, perseverança e habilidade em executar atividades sob tensão, ao contrário do que se acredita socialmente para uma mulher. Estes resultados vão de encontro com o que preconiza Soares (2001, p. 281-285): a questão de mulheres em ciência e tecnologia é o resultado de estruturas institucionais inapropriadas, e não da inaptidão feminina para essas áreas.

No que se refere às peculiaridades de cada curso, o curso de engenharia química é o que possui a maior nota de corte no SISU (Sistema de Seleção Unificada) dentre as engenharias da UFSJ, sendo então um dos cursos mais concorridos e que exige grande dedicação dos discentes.

Já o curso de engenharia de bioprocessos é caracterizado por consideráveis mudanças de curso ou evasão pelo sexo masculino. Devido à complexidade deste curso, muitos estudantes optam por essa engenharia sem saber de fato qual a área de atuação, e também por ter uma nota de corte menor no SISU, facilitando a entrada na universidade. Isto pode ser uma das justificativas da não conclusão do curso pelos homens.

Os cursos de engenharia de telecomunicações e mecatrônica são os mais tecnológicos do campus, onde a presença de mulheres é menor (variando de 13 a 23\%). Observa-se que o curso de telecomunicações é o que apresenta maiores dificuldades para as mulheres. Em mecatrônica, o desempenho do sexo feminino é bem melhor em quase todas as estimativas de tempo de integralização do curso, mostrando que, apesar da representatividade feminina ser menor, as mulheres conseguem se destacar mais na graduação. As engenharias de telecomunicações e mecatrônica possuem basicamente a mesma área, no entanto, assim como na engenharia de bioprocessos, muitos(as) discentes ingressam em telecomunicações sem saber exatamente do que se trata, levando a posteriores evasões. Isso pode justificar também o menor índice de mulheres que se graduam neste curso.

Atualmente, a universidade não disponibiliza de dados referentes ao destino de seus egressos, que seriam interessantes e necessários para saber qual tem sido o destino destas graduandas após sua formação, traçando um perfil por gênero pós-academia. Questões interessantes poderiam ser embargadas neste estudo, contemplando se elas estão ałuando em suas áreas de formação universitária; se experimentam diferença de salários em relação aos homens para um mesmo trabalho; se constituíram família, se possuem filhos e qual a relação entre maternidade e trabalho, além de outras.

\section{A UFSJ em número de mulheres docentes}

A inserção de mulheres no mercado de trabalho se deu por vários fatores, como a tentativa de reduzir os custos de produção, tendo em vista a baixa remuneração oferecida à mulher quando comparada com a do homem; a necessidade econômica - apesar das baixas remunerações, ela é fundamental para garantir seu sustento e o de sua família; suas necessidades de consumo; fator de integração, pois a participação econômica oferece às mulheres uma possibilidade de se integrar na vida pública, ultrapassando o espaço da casa, dentre outros (Caroline Maria LEAL, 2011). 
Devido principalmente às lutas femininas na redução da desigualdade de gênero, as mulheres já têm uma inserção mais favorável no mercado de trabalho, graças ao aumento de sua escolaridade e à diversificação das suas escolhas profissionais (atuando em profissões de áreas historicamente consideradas masculinas como, por exemplo, engenharia, medicina, perícias criminais, dentre outras) e também participam da organização política e sindical, embora ainda timidamente.

Contudo, de forma geral, elas ainda continuam se engajando preferencialmente em profissões de áreas tipicamente femininas (como, por exemplo, assistência social, enfermagem, nutrição e pedagogia), formando os tradicionais guetos femininos, que é uma clara indicação da continuação de padrões de segregação ocupacional (LEAL, 2011).

O trabalho realizado pelos homens é associado a um conhecimento adquirido pela formação profissional, enquanto as mulheres o desenvolvem de acordo com o conhecimento adquirido pela prática do trabalho doméstico. Isso mostra que esta "desqualificação" do trabalho feminino está relacionada a uma construção social do gênero desenvolvida socialmente por meio da educação e do trabalho, levando então mulheres a determinadas áreas de trabalho (Débora de Fina GONZALEZ, 2011).

A partir do estudo realizado nos anos de 2011, 2015 e 2018, foi possível constatar a realidade acima. Os dados mostram que o número de pesquisadoras/docentes da UFSJ se encontra em torno de 38,9\% para todas as áreas (Gráfico 2), com aumento de 5\% em 7 anos (2011 para 2018). A relação de homens e mulheres se manteve praticamente inalterada durante este período, principalmente para as áreas mais tecnológicas.

Em todos os departamentos analisados da UFSJ as maiores concentrações de mulheres estão nas áreas de arquitetura, urbanismo e artes; ciência da educação; psicologia; letras, artes e cultura; e farmácia, medicina, enfermagem e bioquímica, contrapondo os departamentos de engenharia mecatrônica e de telecomunicações (CAP), ciências térmicas e dos fluidos $(0 \%$ de mulheres em 2015), engenharia mecânica e engenharia elétrica.

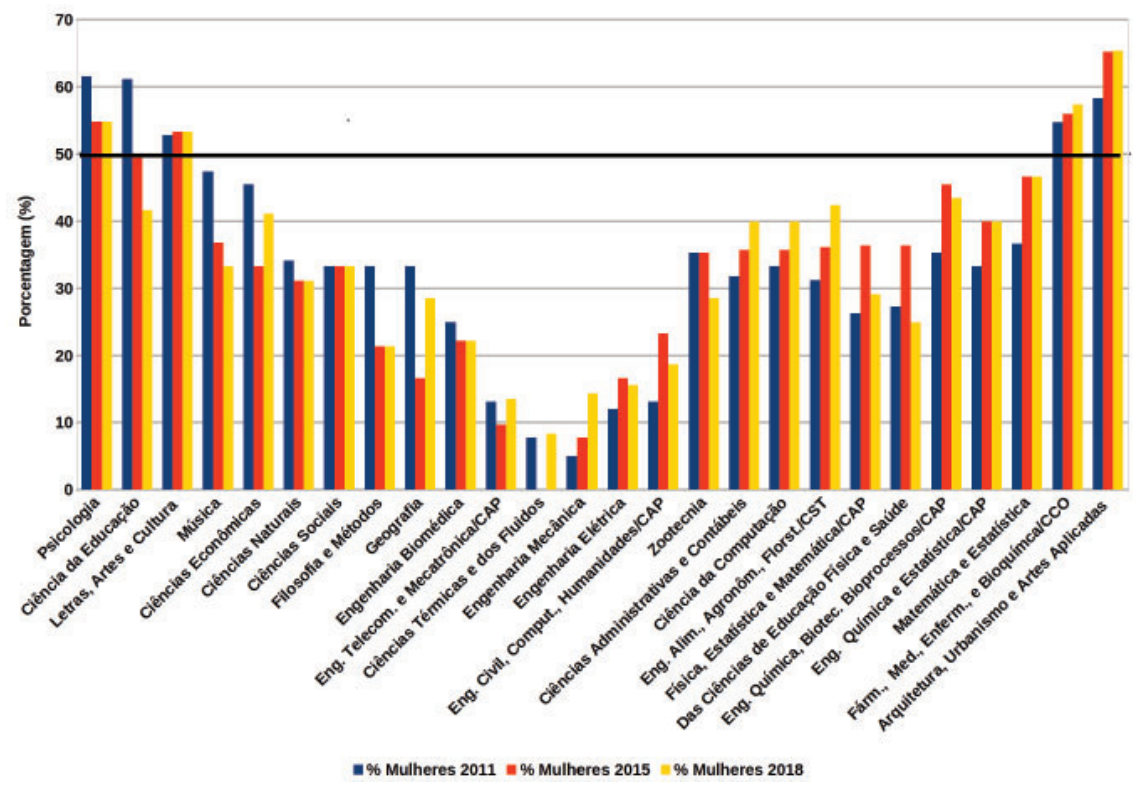

Gráfico 2 - Quadro de mulheres pesquisadoras/docentes da UFS para os anos de 201 1, 2015 e 2018

Fonte: Dados da Pesquisa. ${ }^{2}$

\#PraTodoMundoVer Gráfico comparando o número de mulheres docentes na UFSJ entre 201 1, 2015 e 2018. Das 26 áreas avaliadas, apenas 5 apresentam número de mulheres docentes acima de $50 \%$, sendo essas áreas de humanas e de saúde. Nas áreas de exatas e tecnológicas o número é baixo, em média de 30\%.

Dos docentes ativos do CAP, em 2018, elas totalizam 26\% do número total, distribuídas em seus cinco departamentos. A menor representação feminina encontra-se no departamento das engenharias de telecomunicações e mecatrônica (DETEM), com 13,5\%, e departamento de engenharia civil, computação e humanidades (DETECH), com 18,8\%. Por outro lado, a maioria, ainda escassa comparada ao total, corresponde aos departamentos de química, biotecnologia e engenharia de bioprocessos $(\mathrm{DQBIO})$ e departamento de engenharia química 2 Baseados na lista de docentes, por departamento, disponível on-line no site da UFSJ (dados coletados em 2011 , 2015 e 2018). 
e estatística (DEQUE), com, respectivamente, 43,5 e $40 \%$, os quais abrangem uma das áreas predominantemente feminina, a química e a biologia. O departamento de estatística, física e matemática conta com $29,2 \%$ de mulheres.

Situação semelhante à do CAP é observada para o campus Sete Lagoas (CSL), que oferece os cursos de engenharia agronômica, de alimentos e florestal, contando, em 2018, com 42,4\% de pesquisadoras/docentes mulheres. Por outro lado, o campus Centro-Oeste Dona Lindu (CCO), que oferece os cursos de farmácia, medicina, enfermagem e bioquímica, mostra que as mulheres são maioria, representando $57,4 \%$ do total de docentes. Essa diferença poderia ser explicada pelo fato de que estes cursos estão relacionados com as áreas da saúde, historicamente ocupadas por profissionais do sexo feminino.

\section{Pesquisadoras/docentes: carreira, família e maternidade}

A entrevista realizada com pesquisadoras/docentes da UFSJ/CAP revelou que o ambiente em torno delas, desde a infância, foi um fator decisivo para a escolha e permanência em suas áreas de atuação científica. Os influenciadores mais comuns foram: mídia, livros e filmes de ficção científica, e meios de divulgação científica e de cientistas famosos; habilidade para as exatas desde o ensino fundamental; incentivo de (e/ou inspiração em) professores e pessoas da família (com carreira consolidada nas áreas das exatas); curiosidade e fascinação sobre o assunto.

Quanto à conciliação entre carreira acadêmica, família e filhos, os relatos mostram que existe uma diminuição da dedicação no que se refere à produção científica e a participações em congressos. Além disso, elas narram que as atividades domésticas ainda são realizadas por elas.

Segundo Borges (2014, p. 1-104), a divisão das tarefas domésticas é quase sempre prejudicial às mulheres, pois geralmente são elas que ficam sobrecarregadas com os cuidados do lar e os filhos, e têm dupla jornada no trabalho e em casa. Já o homem, embora também trabalhe fora do lar, não desempenha um número grande de atividades domésticas, nem despende seu tempo com elas. Isso ocorre devido à naturalização de que o sexo feminino deve exercer a função dos cuidados com o lar e filhos. A atribuição destas responsabilidades tidas como femininas produz efeitos diretos na trajetória ocupacional das mulheres, e apresenta-se como entrave para a inserção em cargos de maior responsabilidade e ocupações mais bem remuneradas, como cargos de chefia (GONZALEZ, 2011). Além disso, estudos mostram que os homens só participam de trabalhos na área doméstica quando a mulher exerce alguma atividade remunerada, porém o tempo que eles dedicam a estas tarefas ainda é bastante reduzido. Segundo dados da Fundação Carlos Chagas (2007), os homens gastam em média 10,6 horas por semana nestas atividades, enquanto as mulheres gastam 27,2 horas (LEAL, 201 1).

Ao indagar se o matrimônio e os filhos constituem fatores negativos ou positivos no seu rendimento acadêmico e se já teve que sacrificar alguma boa oportunidade profissional por causa da sua família, dois relatos são ressaltados:

Não são fatores negativos nem positivos, pois é uma balança. Minha intensidade dedicada ao trabalho passou a ser menor. Diminuí minhas idas ao congresso, optei por trabalhos mais próximos de casa, minha produção caiu, a cabeça não funciona mais do mesmo jeito (Entrevistada 1).

Não tenho filhos, mas o casamento demanda muito tempo, mesmo o meu marido sendo da área acadêmica também. Quando fazia o doutorado, estava cheia de compromissos, e, ainda sim, quando eu e meu marido chegóvamos em casa, ele ia ver tv e eu fazer as tarefas de casa (Entrevistada 2).

Das cinco professoras entrevistadas, apenas uma respondeu que sua produção acadêmica continuou a mesma após os filhos. No entanto, diz que é necessário fazer um esforço sobrehumano para conseguir se dividir entre todas as tarefas. As demais entrevistadas relataram uma queda de produção para que conseguissem conciliar sua carreira com a maternidade.

Durante as entrevistas, foi consenso que, para um homem, há menos cobrança e disponibilidade de tempo, havendo mais dedicação à sua carreira. Segundo Zuleica Oliveira (2003), "enquanto que para o homem é natural 'abdicar' da família para se dedicar à carreira, as mulheres têm que lidar todo o tempo com o conflito de ser mãe ou de ser profissional, buscando equilíbrio que é, muitas vezes, difícil de ser atingido". Essa afirmação fica evidente em todos os relatos, indicando um panorama com poucas mudanças, mesmo depois de mais de 15 anos.

Das cinco entrevistadas, duas professoras relataram terem sido assediadas por alunos no início de suas carreiras, gerando constrangimentos. Todas afirmaram também tomar cuidado com os tipos de roupa/maquiagem ao entrar para uma sala de aula, para 'não dar motivos a ninguém' (expressão usada por uma das entrevistadas).

Cabe destacar que uma das professoras, antes de ir para a área acadêmica, teve experiências de muitos anos trabalhando em indústria. Relatou ter sido a única engenheira da planta, e que se sentia muito mais cobrada, e sua opinião era mais difícil de prevalecer. Situação 
semelhante foi relatada por outra entrevistada da área acadêmica, em que muitas vezes em discussões do trabalho homens tiveram que intervir, junto a outros, para que ela pudesse ser ouvida.

Quanto há diferença de comportamento em sala de aula entre homens e mulheres, três professoras relataram que, durante suas aulas, as estudantes geralmente se comportavam mais timidamente, respondendo às perguntas feitas pela professora em voz alta apenas quando possuíam certeza na resposta. Ou, ainda, quando precisavam sanar dúvidas da disciplina, alunas preferiam ir até a sala da professora, ao invés de perguntar, em público, durante a aula.

\section{Consideraçōes Finais}

Os resultados obtidos nesta pesquisa mostram que, apesar do estereótipo masculinizado que as exatas carregam e a falta de apoio demonstrada pela sociedade (família e professores) para que mulheres optem pela área das exatas, as graduandas dos cursos de engenharia da UFSJ/CAP integralizam sua graduação, proporcionalmente, em maior número e em menos tempo que os homens, mesmo nos cursos mais tecnológicos em que elas são minoria.

Os fatores que podem afastar as mulheres das áreas das exatas começam já na infância, quando meninas recebem brinquedos relacionados com tarefas domésticas e/ou cuidado, limitando ou até retardando seu desenvolvimento cognitivo e emocional para atuar nestas áreas. Aspectos importantes nas exatas como a noção espacial, noções de computação e matemática e estudos dos fenômenos da natureza (física e química) podem ser seriamente comprometidos. A falta de incentivo nas exatas é preconizada pela família, escola, sociedade e universidade, levando-as a crer que não possuam aptidões para carreiras tecnológicas e a masculinização do seu ser feminino é a porta aberta para o sucesso nestas áreas.

Os relatos das pesquisadoras/docentes permitem avaliar o grau dos desafios enfrentados na conciliação da família, maternidade e carreira, e os obstáculos enfrentados por mulheres ao ingressarem em cursos de exatas.

Espera-se que este estudo possa estimular a reflexão e a criação de oportunidades iguais para ambos os sexos, o incentivo da família, da escola, da sociedade e do ambiente acadêmico para as discentes que optem por seguir carreira na área das exatas, além de debates acerca da importância de políticas que contribuam para uma igualdade de gênero.

A posteriori, é interessante a análise do destino das formandas participantes desta pesquisa para verificar se as relações de gênero no mercado de trabalho, bem como a tríade carreirafamília-maternidade, traçam ou não o perfil feminino mencionado aqui e discutido na literatura.

\section{Referências}

BELTRAME, Greyce Rocha; DONELLI, Tagma Marina Schneider. "Maternidade e carreira: desafios frente à conciliação de papéis". Aletheia, n. 38-39, p. 206-217, dez. 2012.

BORGES, Elinielle Pinto. Gênero, Ciência e Contexto Regional: analisando diferenças entre docentes da pós-graduação de duas universidades brasileiras. 2014. Dissertação (Mestrado) - Programa de Pós-Graduação em Ciência da Informação, Universidade Federal do Rio de Janeiro, Rio de Janeiro, RJ, Brasil.

CARVALHO, Marília Gomes de; SOBREIRA, Josimeire de Lima. "Gênero nos cursos de engenharia de uma universidade tecnológica brasileira". ARBOR. Revista de Ciência, Pensamiento y Cultura, Madrid, v. 184, n. 733, p. 889-904, set./out. 2008.

FERREIRA, Maria Mary. "O profissional da informação no mundo do trabalho e as relações de gênero". Transinformação, Campinas, v. 15, n. 2, p. 189-201, 2003. Disponível em https://www. scielo.br/scielo.php?script=sci arttext\&pid =S0103-37862003000200007\&lng =es\&nrm =iso\&tlng = pt. Acesso em 21/01/2018.

GONZALEZ, Débora de Fina. Políticas laborais de igualdade de gênero: o Programa Pró-Equidade de Gênero no Brasil. In: SIMPÓSIO GÊNERO E POLÍTICAS PÚBLICAS, 2, 201 1, Londrina, Universidade Estadual de Londrina. Anais... Londrina: UEL, 201 1. p. 1-12.

HAYASHI, Maria Cristina Piumbato Innocentini; CABRERO, Rodrigo de Castro; COSTA, Maria da Piedade Resende da; HAYASHI, Carlos Roberto Massao. "Indicadores da participação feminina em Ciência e Tecnologia". Transinformação [online], v. 19, n. 2, p. 169-187, maio/ago. 2007. Disponível em https://www.scielo. br/scielo.php?pid=S0103-37862007000200007\&script=sci abstract\&tlng=pt. ISSN 0103-3786. http://dx.dol.org/10.1590/S0103-37862007000200007. Acesso em 21/01/2018.

LEAL, Caroline Maria. Divisão social e sexual do trabalho: reprodução das desigualdades de gênero? In: JORNADA INTERNACIONAL DE POLÍTICAS PÚBLICAS, 5, 2011, São Luís, Universidade Federal do Maranhão. Anais... São Luís: UFMA/Programa de Pós-Graduação em Políiticas Públicas, 201 1. p. 1-9. 
MOREIRA, Maria Ligia; VELHO, Lea. "Pós-graduação do Instituto Nacional de Pesquisas Espaciais numa perspectiva de gênero". Cadernos Pagu, Campinas, v. 35, p. 279-308, dez. 2010. Disponível em htttps://www.scielo.br/scielo.php?script=sci_anttext\&pid=\$0104-83332010000200010\&lng=pt\&t lng =pt. Acesso em 21/01/2018.

OLIVEIRA, Zuleica Lopes Cavalcanti de. "Trabalho e gênero: a construção da diferença". Mulher e Trabalho, Porto Alegre, v. 3, 2003. Disponível em https://revistas.dee.spgg.rs.gov.br/index.php/ mulheretrabalho/issue/view/175/showToc. Acesso em 30/01/2019.

PAZELLO, Elaine Toldo. "A maternidade afeta o engajamento da mulher no mercado de trabalho? Um estudo utilizando o nascimento de gêmeos como um experimento natural". Estudos Econômicos, v. 3, n. 36, p. 507-538, jul./set. 2006.

ROCHA, Maria Lúcia Coutinho; ROCHA, Rodrigo Coutinho. "Mulheres brasileiras em posições de liderança: novas perspectivas para antigos desafios". Revista Economia Global e Gestão, v. 1, n. 16, p. 61-80, abr. 2011.

SILVA, Fabiane Ferreira da. Mulheres na ciência: vozes, tempos, lugares e trajetórias. 2012. Tese (Doutorado) - Programa de Pós-Graduação em Educação em Ciências, Universidade Federal do Rio Grande, Rio Grande, RS, Brasil.

SILVA, Márcia Terra da. A engenheira, um estudo empírico da divisão sexual do trabalho. 1992. Dissertação (Mestrado) - Programa de Pós-Graduação em Administração, Fundação Getúlio Vargas, São Paulo, SP, Brasil.

SOARES, Thereza Amélia. "Mulheres em Ciência e Tecnologia: Ascensão Limitada". Química Nova, São Paulo, v. 24, n. 2, p. 281-285, 2001. Disponível em https://www.scielo.br/scielo.php?script=sci anttext\&pid=S0100-40422001000200020\&lng=pt\&nrm=iso\&tlng=pt. ISSN 1678-7064. hittps: //doi. org/10.1590/\$0100-40422001000200020. Acesso em 21/01/2018.

TORRES, Kelly Beatriz Vieira et al. "Inclusão das Mulheres nas Ciências e Tecnologia: ações voltadas para a educação básica". Expressa Extensão, v. 22, n. 2, p. 140-156, 2017.

VENTURI, Gustavo; RECAMÁN, Marisol; OLIVEIRA, Suely de. A mulher brasileira nos espaços público e privado. São Paulo: Fundação Perseu Abramo, 2014.

Rayane Monique Bernardes Loch (rayane_monique@hotmail.com) é mestranda em Bioquímica Aplicada pela Universidade Federal de Viçosa, Engenheira Química (12/2017) e Bacharel em Ciência e Tecnologia (07/2017) pela Universidade Federal de São João Del-Rei. Atualmente trabalha com bioquímica de proteínas e peptídeos. Membro do grupo de pesquisa "Proteína e peptídeos: Análise proteômica aplicada ao agronegócio".

Kelly Beatriz Vieira Torres (kbtorres@ufsj.edu.br) é doutora em Astrofísica pela UFMG, PósDoutora em Astrofísica pelo Observatório Real da Bélgica. Professora de Física do Departamento de Estatística, Física e Matemática do Campus Alto Paraopeba da UFSJ. Coordenadora de projetos que envolvem a igualdade de gênero nas áreas das Ciências, Tecnologia, Engenharia e Matemática. Representante brasileira da ONG Internacional Greenlight for Girls, sediada na Bélgica.

Carolina Reciate Costa (Carolina.Reciate@hotmail.com) é estudante de Engenharia de Bioprocessos no Campus Alto Paraopeba da UFSJ, aluna de iniciação científica nas áreas de Bioinformática, Nanotecnologia e Redes Complexas. Bolsista de projeto de extensão voltado para inclusão de mulheres nas Ciências, Tecnologia, Engenharia e Matemática. 


\section{COMO CITAR ESSE ARTICO DE ACORDO COM AS NORMAS DA REVISTA}

LOCH, Rayane Monique Bernardes; TORRES, Kelly Beatriz Vieira; COSTA, Carolina Reciate. "Mulher, esposa e mãe na ciência e tecnologia". Revista Estudos Feministas, Florianópolis, v. 29, n. 1, e61470, 2021.

\section{CONTRIBUIÇĀO DE AUTORIA}

Rayane Monique Bernardes Loch - realizou a pesquisa quanto ao número de ingressos e egressos de ambos os sexos nos cursos de engenharia para os anos 2008-2016/1 e entrevista com pesquisadoras/docentes do campus. Participou da análise destes dados. Redigiu a Introdução, Metodologia, parte dos resultados e Considerações Finais. Escrita e revisão do texto baseadas nas sugestões/questionamentos do parecerista 2.

Kelly Beatriz Vieira Torres - realizou as pesquisas e análise do número de professoras docentes na UFSJ. Participou da análise dos dados do número de ingressos e egressos de ambos os sexos nos cursos de engenharia para os anos 2008-2017. Elaborou as figuras do artigo. Revisou e corrigiu o texto elaborado por Rayane Bernardes. Redigiu os resultados referentes às pesquisas realizadas por ela mesma. Escrita e revisão do texto baseadas nas sugestões/questionamentos do parecerista 2.

Carolina Reciate Costa - Atualizou os dados do número de ingressos e egressos de ambos os sexos nos cursos de engenharia para os anos 2016/2 e 2017, bem como o número de professoras docentes na UFSJ para o ano de 2018. Revisou e corrigiu o texto final.

\section{FINANCIAMENTO}

Não se aplica.

\section{CONSENTIMENTO DE USO DE IMAGEM}

Não se aplica

\section{APROVAÇĀO DE COMITÊ DE ÉTICA EM PESQUISA}

Não se aplica.

\section{CONFLITO DE INTERESSES}

Não se aplica.

\section{LICENÇA DE USO}

Este artigo está licenciado sob a Licença Creative Commons CC-BY 4.0 International. Com essa licença você pode compartilhar, adaptar, criar para qualquer fim, desde que atribua a autoria da obra.

\section{HISTÓRICO}

Recebido em 08/02/2019

Reapresentado em 01/12/2019

Aprovado em 09/06/2020 